\title{
Structure and fractal dimensions of root systems of four co-occurring fruit tree species from Botswana
}

\author{
Armin L. Oppelt ${ }^{\mathrm{a}, *}$, Winfried Kurth ${ }^{\mathrm{b}}$, Helge Dzierzon ${ }^{\mathrm{b}}$, Georg Jentschke \\ and Douglas L. Godbold ${ }^{\mathrm{c}}$ \\ ${ }^{\text {a }}$ Georg-August-Universität Göttingen, Institut für Forstbotanik, Büsgenweg 2, D-37077 Göttingen, Germany \\ ${ }^{\mathrm{b}}$ Georg-August-Universität Göttingen, Institut für Forstliche Biometrie und Informatik, Büsgenweg 4, D-37077 Göttingen, Germany \\ ${ }^{c}$ School of Agriculture and Forest Science, University of Wales, Bangor, Gwynedd LL57 2UW, UK
}

(Received 1 February 1999; accepted 29 October 1999)

\begin{abstract}
Coarse root systems of four different fruit tree species from southern Africa were completely excavated and semi-automatically digitized. Spatial distributions of root length were determined from the digitally-reconstructed branching systems. Furthermore, the fractal characteristic of the coarse root systems was shown by determining the box-counting dimensions. These quantitative methods revealed architectural differences between the species, probably due to different ecophysiological strategies. For fine root samples, which were taken before digging out the whole systems, fractal analysis of the planar projections showed no significant inter-species differences. Methodologically, the study underlines the usefulness of digital 3-D reconstruction in root research.
\end{abstract}

root / digital reconstruction / fractal / architectural analysis / coarse root

Résumé - Structures et dimensions fractales des systèmes racinaires provenant de quatre espèces d'arbres fruitiers de Botswana. Des systèmes de grosses racines, provenant de quatre espèces différentes d'arbres fruitiers d'Afrique du Sud, ont été complètement déterrés et digitalisés semi-automatiquement. Les distributions spatiales des longueurs de racines ont été calculées à partir des maquettes informatiques reconstituées. En outre, le caractère fractal des systèmes de grosses racines a été prouvé par une détermination de dimensions utilisant la méthode du comptage de boites. Ces méthodes quantitatives révèlent des différences architecturales entre les espèces, résultant probablement de différentes stratégies écophysiologiques. Pour les échantillons de racines fines, obtenus avant l'excavation des systèmes complets, l'analyse fractale des projections planes n'a pas montré de différences significatives entre les espèces. Concernant la méthode, l'étude fait apparaître l'apport de la reconstruction digitale 3-D dans le domaine de la recherche sur les appareils racinaires.

racine / reconstruction digitale / fractal / analyse architectural / racine gros

\section{INTRODUCTION}

Investigations of root structure of tropical tree species are few. However, information on the rooting structure of locally and economically important species can be of great benefits. This is especially the case for fruit trees, where knowledge of root structure can provide a solid basis for sustainable use and integration into agriculture.

* Correspondence and reprints

Tel. 49551 39-9479; Fax. 49551 39-2705; e-mail: aoppelt1@gwdg.de 
Qualitative architectural analysis was first developed for tree crowns by Hallé et al. [22]. Similar work on roots, aiming at an understanding of root system architecture as an indicator of growth strategy, was initiated by several authors, e.g. [18, 20]; see [5, 6, 11, 13, 17, 23] for studies on root systems of conifers. Morphological studies on root systems of angiosperms of temperate regions, e.g. [32], and on palms [24, 26] have also been carried out. Digitizing and computer-based analysis techniques can considerably improve the efficiency and reproducibility of such investigations (e.g. [3, 7, 25]). Numerous dynamic models of root growth have been developed on these grounds in the past $[4,8,9,31,36]$.

Various attempts have been made in the literature to quantify aspects of order in the growth forms of vegetation. One approach, dating back to the seminal work of Mandelbrot [33], determines the fractal dimension of a given morphological structure in space. Provided the fractal dimension is well-defined for the structure under consideration, it serves as a measure of occupation of space at different length scales and as an indicator of certain forms of self-similarity (see [14] and [16] for mathematical details). Besides its application to various abiotic structures [1], the concept of fractal dimension has been applied to above-ground branching patterns of trees [41, $44,45,40,29]$, to rhizomatous systems [40] and to root systems of several plant species. Berntson [2] gives a review of the attempts to determine fractal dimensions of root systems. Beginning with Tatsumi et al. [42], Berntson [2] notes that in all reviewed work dealing with real root structures (not just with abstract growth models), dimension estimation was only applied to planar projections of the root systems. Eshel [15] was to our knowledge the first to determine a fractal dimension $d$ of a complete root system embedded in full 3-D space. He made equidistant gelatin slices of a single root system of the dwarf tomato Lycopersicum esculentum and used image processing and manual box counting to estimate $d$ for the full system and for horizontal and vertical intersection planes.

For our sample root systems from four different tree species, we use a technique for complete digital reconstruction of 3-D branching systems. With such a "virtual tree" [38], all sorts of topological and geometrical analysis, amongst them fractal dimension estimation, can be carried out with ease. Similar digital plant reconstructions have been realized for the above-ground parts of a walnut tree [39] and for the root system of an oak tree [12]. Godin et al. [19] also develop techniques for encoding, reconstructing and analyzing complete 3-D plant architectures. In our study, 3-D reconstruction of root system architecture serves as a means to identify and to quantify differences in the rooting behaviour of four different species growing under similar environmental conditions. We present only a small subset of the possible analysis options available for digital plant reconstructions; much more can be done.

\section{MATERIALS AND METHODS}

\subsection{Site description}

The investigation site is located on sandveld near Mogorosi (Serowe Region, Central District, Botswana) between longitude $26^{\circ} 36.26^{\prime}$ and $26^{\circ} 36.70^{\prime} \mathrm{E}$ and latitude from $22^{\circ} 25.09^{\prime}$ to $22^{\circ} 25.30^{\prime} \mathrm{S}$. The vegetation can be described as bushveld with Acacia spp. and Terminalia spp. as characteristic species. The soils, mainly originating from sandstones, can be, according to the USDA-Soil Taxonomy, characterised as poorly developed Entisols. A very low fertility status, especially in organic carbon, even in the surface horizon, and low iron contents are characteristic in that region. The low amount of rainfall [10], which is about $430 \mathrm{~mm} / \mathrm{yr}$, and, additionally, high evapotranspiration, also during the growing season, are responsible for low crop yields.

\subsection{Recording of root structure}

The architecture of in situ grown coarse root systems of the fruit tree species Strychnos cocculoides [Loganiaceae] (Mogorogorwane), Strychnos spinosa (Morutla) and Vangueria infausta [Rubiaceaea] (Mmilo) as well as from the shrub Grewia flava [Tiliaceae] (Moretlwa) was studied. "Coarse roots" were defined by a diameter $\geq 3 \mathrm{~mm}$. For roots below this threshold, a reconstruction of spatial orientation and branching would not have been possible with our method.

Five coarse root systems of each species were investigated. The whole coarse root systems were excavated by manual digging. After exposure of the roots, they were divided and permanently marked with white ink into segments of different length, at each point where growth direction changed. The vertical angle and the magnetic bearing (azimuth) of each segment was determined and their individual length was recorded by a digital compass (TECTRONIC 4000, Breithaupt, Kassel - Germany) creating an ASCII-file (L-file).

After measurement of the original position in the field, the coarse roots were removed and the diameters of each single segment of the complete root system measured with a digital caliper (PM 200, HHW Hommel - 
Switzerland) creating a corresponding file (D-file) to each L-file.

Both raw data sets (L- and D-files) were merged by an interface software creating the final code for reconstruction. For encoding the full geometrical and topological structure of the root systems (lengths, orientations and diameters of all segments and mother-segment linkages) we used the dtd code (digital tree data format [28, 30]). The dtd files, each representing one complete root system, were generated semi-automatically as described above, and served as input for the software GROGRA 3.2 $[28,29]$ for 3-D reconstruction of the excavated systems.

The GROGRA software is suitable for reconstruction of a three dimensional topological and geometrical structure, so that a visual comparison between reality in the field and the generated description files from measurements can be obtained. Furthermore, GROGRA provides several algorithms for different types of analysis of 3-D branching structures (determination of root density in given spatial grids, fractal dimension, tapering, classification according to branching order). Here we concentrate on overall root system structure and on fractal analysis; an investigation of tapering and cross-section areas will be presented in a forthcoming paper.

To describe the internal topology of the branching systems, a developmental topological concept of branching order was used: The order of the tap root (if it exists) is 0 , and an $n$-th order root has branches of order $n+1$. The branching order was calculated for each segment automatically by GROGRA.

\subsection{Fine roots}

Before excavation of the coarse roots, systematic fine root sampling was carried out around every tree with a soil auger ( $\varnothing 80 \mathrm{~mm}$, volume 1 litre). Ninety six samples per tree were collected. Core samples were taken on the cross points between three concentric circles $(r=1,2$, $3 \mathrm{~m}$ ) with eight centripetal lines (N, NE, E, SE, S, SW, $\mathrm{W}$ and $\mathrm{NW})$ in four depths (0-20, 20-40, 40-60 and $60-80 \mathrm{~cm}$ ). Roots were removed by dry sieving and separated from roots originating from other species. For morphological analysis, 15 fine root samples per tree were chosen randomly and fixed in isopropanol. Fractal analysis of the fine roots was carried out using a flat bed scanner (HP 4Jc) with the software WinRHIZO 3.10.

\subsection{Fractal dimension analysis}

Fractal dimension can be conceived as a measure how intensely an object fills the space [1]. A value of 1 corre-

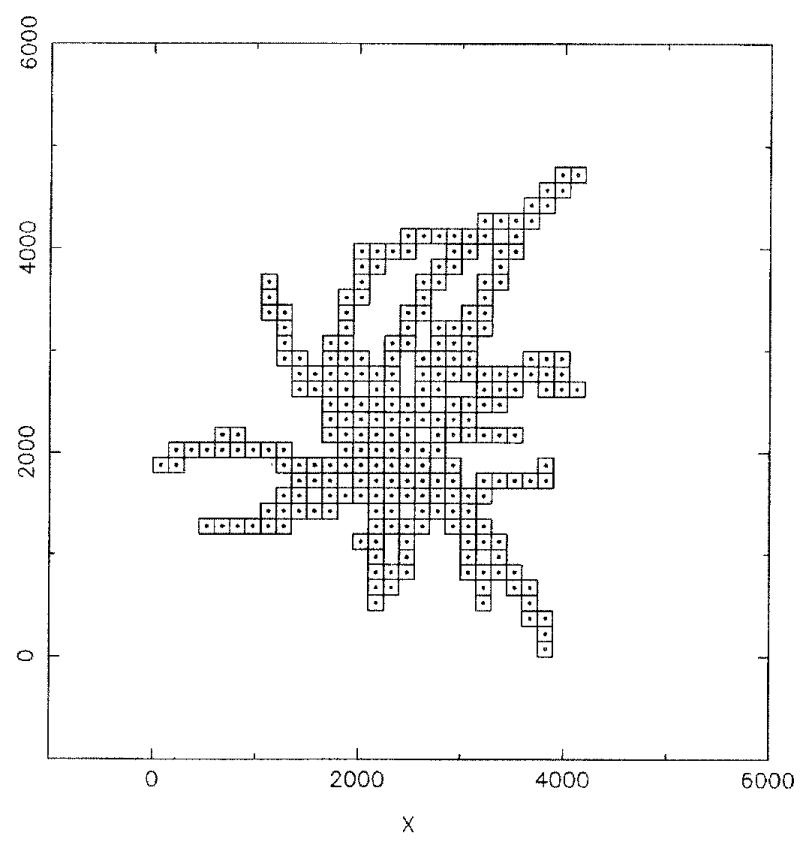

Figure 1. Projection of an analysed root system in the $150 \mathrm{~mm}$ resolution grid.

sponds to a single Euclidean line, 2 to a planar object, and a value of, say, 1.5 characterizes an object filling "more" space than a line, but "less" than a plane. For practical purposes, the fractal dimension is commonly approximated by the box counting dimension $D$ [16]. $D$ is estimated by superimposing a mesh consisting of cubic boxes with length $s$ (= resolution or scale of the mesh), and by determining the number $N(s)$ of boxes containing a part of the object under consideration (figure 1). This counting is repeated for a set of scales from a given range, and $D$ is obtained as the negative slope of the regression line in the log-log plot of $N(s)$ versus $s$ (e.g. [1]), see figure 2.

For determining the regression line, we used unweighted least squares, though the data points in the box-count plot are not independent from each other and the statistical error will normally not be uniform in $s$. The obtained coefficients of determination $R^{2}$ are therefore usually higher than with independent data points; the models appear to fit better than they actually do [37, 43]. We nevertheless applied the simple least-squares procedure, since the determination of statistical precision of dimension estimators is a rather exacting task and was realized in the literature only under simplifying assumptions [21, 43]. Moreover, it is problematic to compare fractal dimensions estimated with different methods or obtained from different ranges of scales [16]. Hence our 


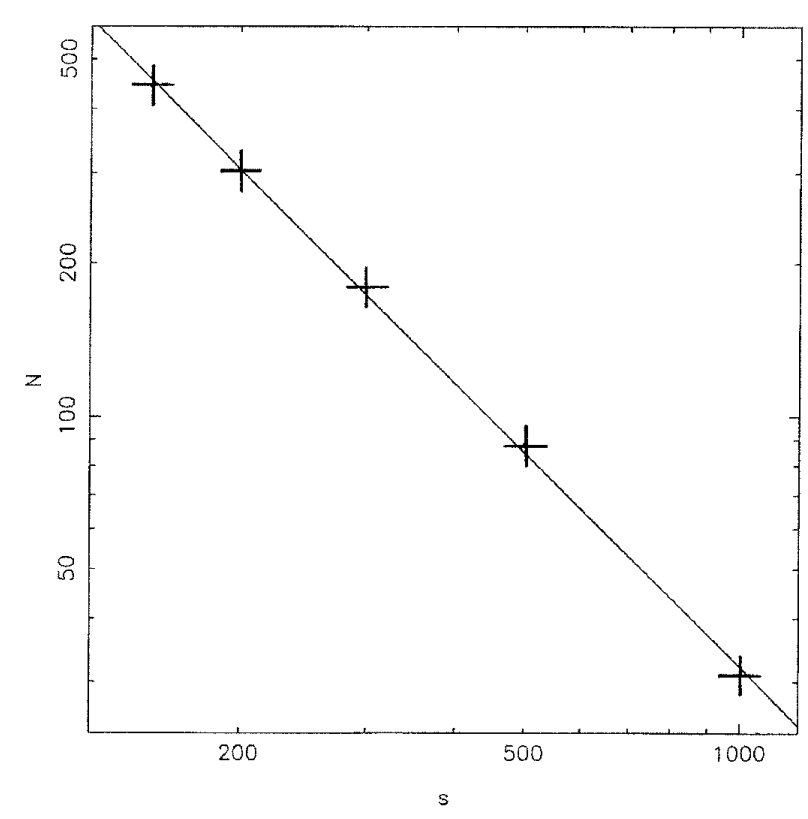

Figure 2. Doubly logarithmic plot of number of boxes (N) vs. resolution (s).

numerical results have to be relativized, but can give some information when compared with each other, since we used a fixed set of scales for all samples.

We have decided to use a lowest grid resolution of $1 \mathrm{~m}$, which falls just under the order of magnitude of the overall root system extension, and a highest resolution of $15 \mathrm{~cm}$, which lies in the order of magnitude of the mean interbranching distance occurring in our samples (cf. table I). Pretests have shown that when using even higher resolutions, the obtained dimension value becomes unstable and eventually falls to a value near 1 . Like for other natural phenomena, and in contrast to mathematically defined self-similar sets, a fractal behaviour can be obtained only within a limited range of scales [27]. Between the two extremes, we have added only three further resolution values $(50,30,20 \mathrm{~cm})$ to keep the amount of calculation time reasonable. A sensitivity analysis carried out at one of the samples showed no gain of precision of the obtained dimension value when 10 more intermediate resolutions were used - an observation which is in accordance with theory [21].

In addition to the box-counting dimension $D$ calculated on the basis of the 3-D reconstruction of the coarse root systems, we have determined the dimension $D_{x y}$ of the parallel projection of the whole system into a horizontal plane, using the same set of grid resolutions.

\subsection{Determination of tree age}

Tree age was estimated by counting the number of rings at the root collar. Root collar sections were carefully sanded and the number of rings counted using a binocular. As the Serowe area has only one rainy season per year, each ring was considered to be one year's growth.

\section{RESULTS}

\subsection{General description of the root systems excavated}

Table I gives an overview on basic parameters of all the investigated root systems. All data were calculated with the help of GROGRA 3.2 [28].

Analysis of growth rings showed that the trees have a wide range of ages: Grewia flava (13-25 years), Strychnos cocculoides (13-29 years), Strychnos spinosa (12-20 years) and Vangueria infausta (19-36 years). As a consequence, parameters like the root collar diameter $(27-140 \mathrm{~mm})$, the total root length $(11-207 \mathrm{~m})$, the extension in North-South-direction (1.1-10.0 m) as well as in West-East-direction (0.7-10.1) and the maximal radial extension $(1.2-6.0 \mathrm{~m})$ varied strongly between individuals in a species (see table I). Although all the excavated root systems represent different ages, species dependent characteristics could be identified.

\subsection{Description of root systems}

To demonstrate the typical features, two root systems of each species with different ages were chosen. One lateral view (figure 3) and one view of each root system from above (figure 4) is shown. The lateral view shows the system from the east, i.e. south is on the left and north on the right hand side.

In Grewia flava coarse root systems (figure 3), most of the first order laterals were almost horizontally orientated and concentrated in the upper soil layers, even when a deep tap root had developed. Long first order laterals showed downward growth only at distance from the shoot base. Vertical roots were mostly second or even higher order roots. Long tap roots were sometimes present but were not typical for a Grewia root system. Adventitious roots originating from the shoot were a typical feature of old Grewia flava root systems.

In contrast to the other investigated species, individuals from both Strychnos (figure 3) species developed a 
Table I. Basic parameters of individual root systems excavated.

\begin{tabular}{|c|c|c|c|c|c|c|c|c|c|c|}
\hline species & id $\left.^{1}\right)$ & $\begin{array}{l}\text { Age } \\
{[\mathbf{y r}]}\end{array}$ & $\begin{array}{l}\left.\mathbf{r c d}^{2}\right) \\
{[\mathbf{m m}]}\end{array}$ & $\begin{array}{l}\left.\operatorname{trl}^{3}\right) \\
{[\mathbf{m}]}\end{array}$ & $\left.r_{\max }^{4}\right)$ & $\begin{array}{c}z_{\max } \\
{[\mathrm{m}]}\end{array}$ & $\left.b_{\max }^{6}\right)$ & $\begin{array}{l}\left.\mathbf{i b d}^{7}\right) \\
{[\mathbf{m m}]}\end{array}$ & $\begin{array}{c}\left.\mathbf{r l d}^{\mathbf{8}}\right) \delta \\
{\left[\mathbf{c m} / \mathbf{d m}^{3}\right]}\end{array}$ & $\begin{array}{c}\left.\mathbf{r v d}^{\mathbf{9}}\right) \\
{\left[\mathbf{c m}^{3} / \mathbf{c m}^{3}\right]}\end{array}$ \\
\hline \multirow[t]{5}{*}{ Grewia flava } & 203 & 25 & 97 & 191 & 5.7 & 2.3 & $3+a d$ & 656 & 0.0806 & 0.0035 \\
\hline & 206 & 21 & 65 & 73 & 3.3 & 2.6 & $3+a d$ & 459 & 0.0842 & 0.0033 \\
\hline & 213 & 18 & 58 & 59 & 3.3 & 3.2 & 3 & 554 & 0.0522 & 0.0016 \\
\hline & 214 & 14 & 32 & 20 & 1.6 & 2.0 & $3+a d$ & 183 & 0.1219 & 0.0032 \\
\hline & 215 & 13 & 27 & 8 & 1.5 & 2.0 & $2+\mathrm{ad}$ & 33 & 0.0579 & 0.0019 \\
\hline mean & & 18 & 56 & 70 & 3.1 & 2.4 & & 377 & 0.08 & 0.003 \\
\hline & & 5.0 & 28.2 & 72.4 & 1.7 & 0.5 & & 174.1 & 0.03 & 0.00 \\
\hline median & & 18 & 58 & 59 & 3.3 & 2.3 & & 459 & 0.08 & 0.003 \\
\hline \multirow[t]{5}{*}{ Strychnos cocc. } & 405 & 23 & 56 & 38 & 2.5 & 2.0 & 3 & 23 & 0.1011 & 0.0065 \\
\hline & 409 & 15 & 67 & 25 & 4.4 & 1.5 & 2 & 97 & 0.0263 & 0.0031 \\
\hline & 412 & 17 & 48 & 19 & 3.9 & 1.9 & 2 & 161 & 0.0207 & 0.0018 \\
\hline & 425 & 29 & 68 & 51 & 3.4 & 1.7 & 3 & 406 & 0.0814 & 0.0068 \\
\hline & 426 & 13 & 44 & 21 & 3.0 & 1.8 & 2 & 103 & 0.0403 & 0.0027 \\
\hline mean & & 19 & 57 & 31 & 3.4 & 1.8 & & 158 & 0.05 & 0.004 \\
\hline & & 6.5 & 10.9 & 13.5 & 0.74 & 0.2 & & 71.4 & 0.04 & 0.00 \\
\hline median & & 17 & 56 & 25 & 3.4 & 1.8 & & 103 & 0.04 & 0.003 \\
\hline \multirow[t]{5}{*}{ Strychnos spinosa } & 501 & 20 & 72 & 114 & 6.0 & 1.7 & 2 & 426 & 0.0577 & 0.0029 \\
\hline & 508 & 12 & 60 & 43 & 4.2 & 3.1 & 2 & 396 & 0.0248 & 0.0021 \\
\hline & 509 & 17 & 40 & 11 & 1.4 & 2.1 & 2 & 39 & 0.0764 & 0.0073 \\
\hline & 510 & 15 & 64 & 49 & 2.8 & 1.3 & 2 & 138 & 0.1595 & 0.0096 \\
\hline & 511 & 12 & 44 & 35 & 2.7 & 1.7 & 2 & 194 & 0.0880 & 0.0038 \\
\hline mean & & 15 & 56 & 50 & 3.4 & 2.0 & & 239 & 0.08 & 0.005 \\
\hline & & 3.4 & 13.6 & 38.4 & 1.8 & 0.7 & & 194.1 & 0.05 & 0.00 \\
\hline median & & 15 & 60 & 43 & 2.8 & 1.7 & & 194 & 0.08 & 0.004 \\
\hline \multirow[t]{5}{*}{ Vangueria infausta } & 706 & 36 & 140 & 207 & 5.1 & 2.5 & 5 & 309 & 0.1032 & 0.0062 \\
\hline & 708 & 21 & 86 & 52 & 3.6 & 2.4 & 4 & 178 & 0.0520 & 0.0030 \\
\hline & 711 & 19 & 48 & 25 & 1.7 & 1.3 & 5 & 142 & 0.2037 & 0.0106 \\
\hline & 712 & 25 & 60 & 25 & 1.2 & 1.8 & 4 & 120 & 0.2817 & 0.0123 \\
\hline & 713 & 25 & 70 & 35 & 1.5 & 1.1 & 4 & 252 & 0.4132 & 0.0177 \\
\hline mean & & 25 & 81 & 69 & 2.6 & 1.8 & & 200 & 0.21 & 0.010 \\
\hline std & & 6.6 & 35.9 & 78.2 & 1.7 & 0.6 & & 70.1 & 0.14 & 0.01 \\
\hline Median & & 25 & 70 & 35 & 1.7 & 1.8 & & 178 & 0.20 & 0.011 \\
\hline
\end{tabular}

1) Identifying number of individual.

2) Root collar diameter.

3) Total root length.

4) Maximal radius of the whole root system.

5) Maximal depth of the whole root system.

6) Branching order; ad: adventitious roots.

7) Inter branching distance (mean of all branching orders).

8) Root length density ( $\mathrm{rld}=\operatorname{trl} / \pi r_{\max }^{2} z_{\max }$ ).

9) Root volume density ( $\mathrm{rvd}=$ total root volume $/ \pi r_{\max }^{2} z_{\max }$ ).

pronounced and deeply penetrating tap root showing intensive secondary growth.

In the case of $S$. cocculoides the first order laterals were inserted along the whole tap root, with no obvious pattern of longer or shorter roots. Most of the long first order laterals are bow-shaped because of change in growth direction with time.

The typical Strychnos spinosa root architecture had similar features to that of $S$. cocculoides (intensive tap root), but showed a strong decline in length of first order roots from upper to deeper soil layers, which clearly distinguishes both species. The branching intensity was extraordinarily low, as the coarse roots did not develop roots of higher branching order than 2 in all the excavated individuals.

In comparison to the above described species, the first order roots of Vangueria infausta showed a more plagiogeotropic growth direction. First order roots of 


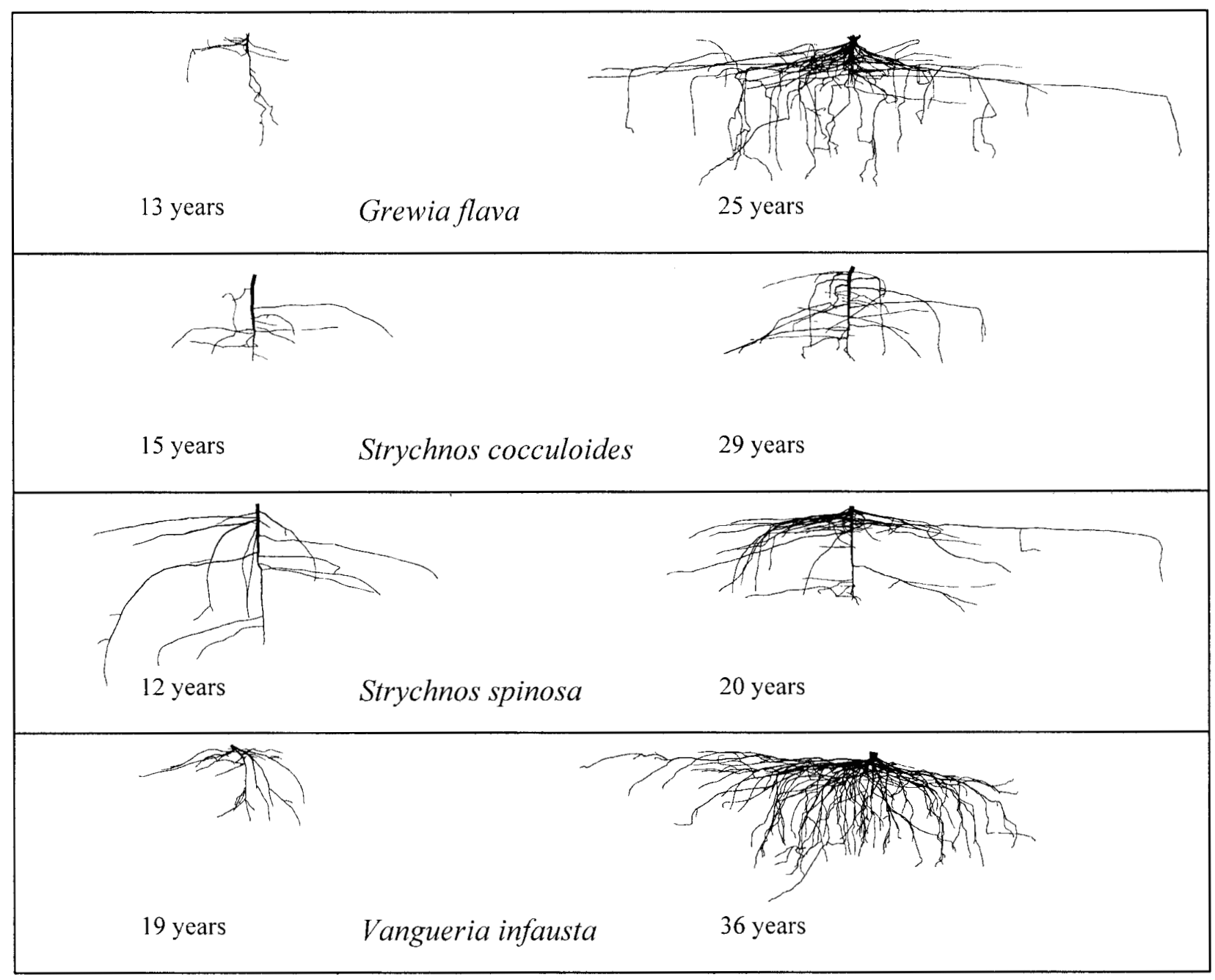

Figure 3. Lateral view of coarse root systems from Grewia flava, Strychnos cocculoides, Strychnos spinosa and Vangueria infausta in different age classes. Scale 1:100.

Vangueria infausta are more frequently and intensively branched into second and higher order roots than the other species investigated. Coarse root systems from this species develop a relatively dense network.

We checked the tightness of correlation between age and other basic parameters. For the number of terminal roots, total root length and collar diameter, respectively, $v s$. age, clear linear dependencies governed the total population of investigated root systems $\left(R^{2}=0.58,0.42\right.$, 0.61 respectively). When the fitting was done for each species separately, the correlation did normally increase ( $R^{2}$ between 0.63 and 0.98 ), with the exception of Strychnos spinosa with a weak age dependence of the number of terminal roots and of total root length $\left(R^{2}=\right.$
0.24 , resp. 0.34), and with the exception of both Strychnos species in the case of collar diameter $v s$. age (S. cocculoides: $R^{2}=0.33$, S. spinosa: $R^{2}=0.15$ ).

For other global parameters, like rooting depth and maximal radius of the system, as well as for root length density and mean interbranching distance, no clear age trend could be statistically identified in the total population, though some of these parameters were well correlated with age when only the representatives of one species were considered (Strychnos cocculoides: $R^{2}=0.61$ and 0.78 for root length density and root volume density increasing with age, resp., and in Grewia flava and Vangueria infausta: $R^{2}=0.77$, resp. 0.73 , for mean interbranching distance growing with age). 


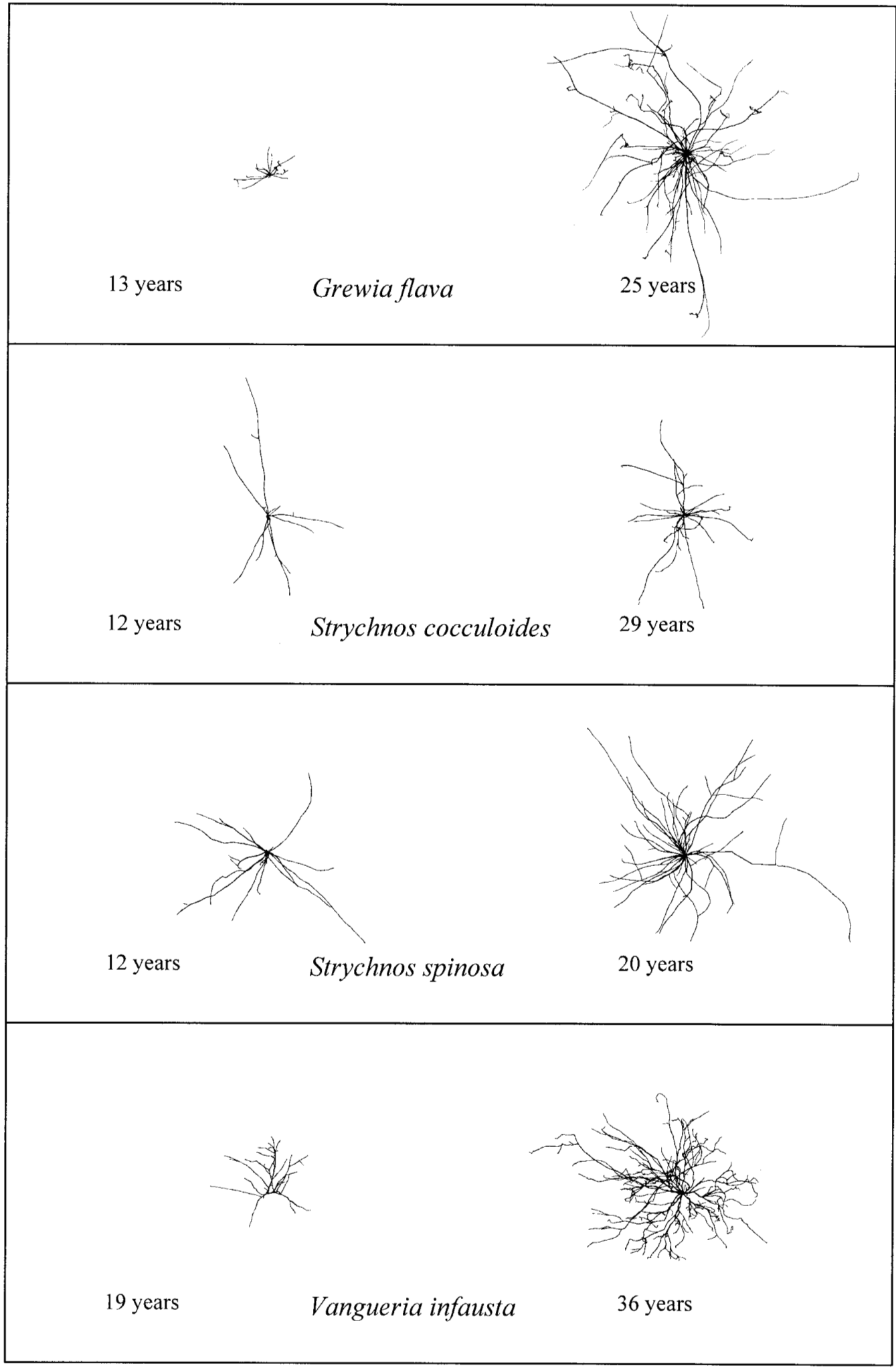

Figure 4. View from above of four coarse root systems from Grewia flava, Strychnos cocculoides, Strychnos spinosa and Vangueria infausta in different age classes. Scale 1:200. 


\subsection{Quantitative analysis of coarse root systems}

For quantifying distinctive features of the coarse root architecture and for description of species dependent rooting behaviour, the horizontal and vertical distribution of the lengths of the coarse roots is shown (figures 5 and 6 ). Since the different ages of the selected trees lead to a considerable variation of horizontal and vertical extension of the single root systems, all values are always expressed as percentage of the total root length of the whole system.

Although all the species differed in root architecture, radial distribution is quite similar in all four species. For all species a maximum of root length density was found near to the center, i.e. within $0.5 \mathrm{~m}$ distance from the trunk. However, a high variation was found between individuals of Grewia flava $\left(\operatorname{std}_{0.5 \mathrm{~m}}=28.3\right)$ and Vangueria infausta $\left(\operatorname{std}_{0.5 \mathrm{~m}}=22.6\right)$. Furthermore, both of these species show a second peak of variation at a distance of $1.5 \mathrm{~m}$ for Grewia flava $\left(\operatorname{std}_{1.5 \mathrm{~m}}=6.5\right)$ and at $2.0 \mathrm{~m}$ for Vangueria infausta $\left(\operatorname{std}_{2.0 \mathrm{~m}}=28,3\right)$. In contrast, both Strychnos species have a more homogeneous radial distribution of coarse roots with a lower range of variation. This was more pronounced in Strychnos spinosa $\left(\operatorname{std}_{0.5 \mathrm{~m}}=12.4\right)$ than in $S$. cocculoides $\left(\operatorname{std}_{0.5 \mathrm{~m}}=\right.$ 6.4), which shows the most homogeneous radial coarse root distribution $\left(\operatorname{std}_{\min }=0.3,350<d<400 \mathrm{~cm}\right)$ among the investigated species (figure 5).

Contrary to the radial distribution of the coarse roots, the vertical distribution shows marked differences between species. Wheras Grewia flava, Strychnos spin$o s a$ and Vangueria infausta reach their maximum root

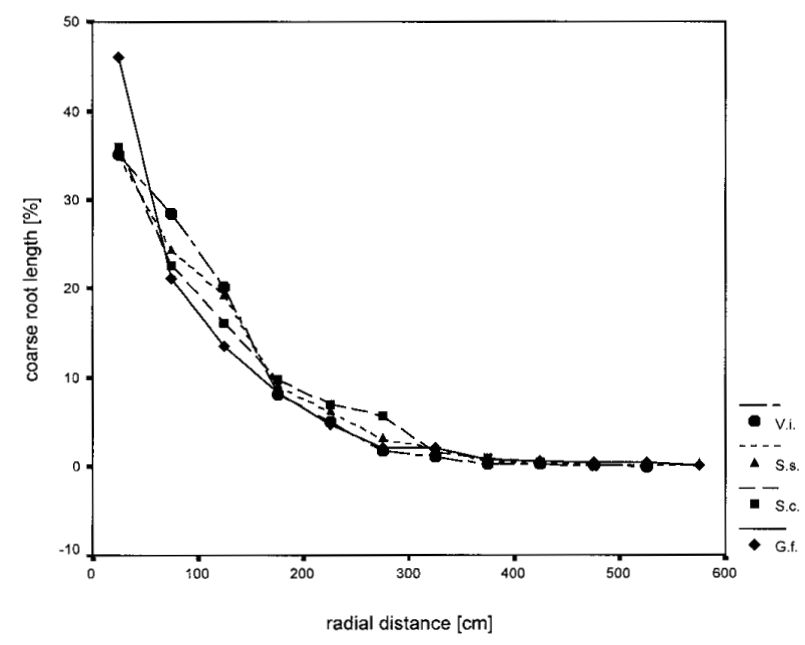

Figure 5. Radial distribution of coarse roots from Grewia flava (G.f.), Strychnos cocculoides (S.c.), Strychnos spinosa (S.s.) and Vangueria infausta (V.i.).

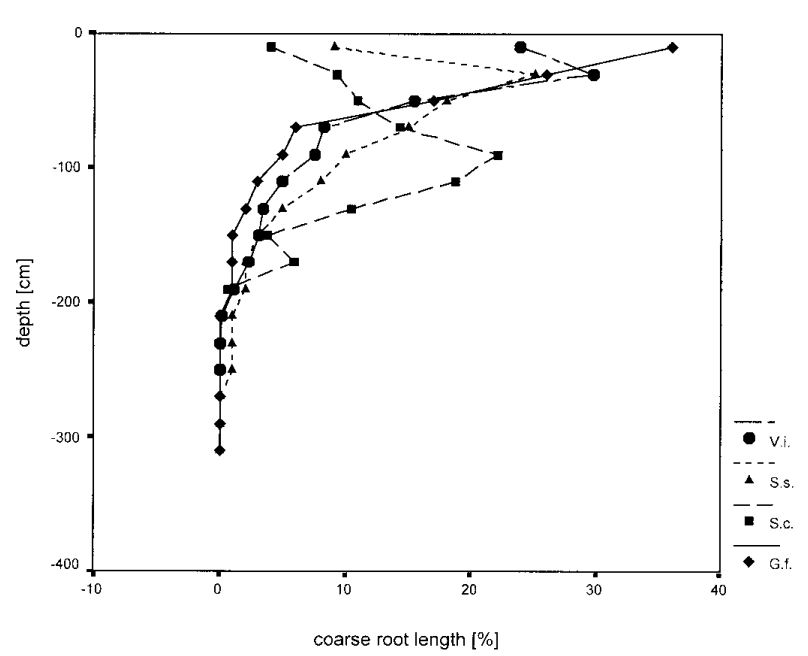

Figure 6. Vertical distribution of coarse roots from Grewia flava (G.f.), Strychnos cocculoides (S.c.), Strychnos spinosa (S.s.) and Vangueria infausta (V.i.).

length in a depth of $40 \mathrm{~cm}$, Strychnos cocculoides exhibits a peak of coarse root density in a depth of $100 \mathrm{~cm}$ (figure 6).

\subsection{Fractal geometry}

\subsubsection{Coarse roots}

The fractal dimension was approximated by the box counting dimension $(D)$. The value of $D$ can range from 0 to 3 ; the value of 0 occurs for an empty space or for a point-like structure, whereas the value of 3 is obtained when a three dimensional space is completely filled. $D$ can be interpreted as a measure of the spatial distribution of coarse root systems. The results of dimension analysis are shown in table II. The values of $D$ are dependent on the chosen range of scaling (150-1000 $\mathrm{mm}$ in all cases). The $R^{2}$ for the underlying $\log -\log$ relation was in all cases around 0.99 , hence in the considered range of resolutions the root systems can be seen as fractals. The same holds for their projections into a horizontal plane (xy-plane), with $D_{x y}$ as the resulting box counting dimension. Since the root systems differ considerably in their spatial extension, in the last column of table II we show the number of boxes $N$ checked at highest resolution during the 3-D.

The mean value of the box counting dimension shows clear differences between Strychnos cocculoides with the lowest and Vangueria infausta with the highest $D$. This was confirmed by a one-factor ANOVA with subsequent 
Table II. Fractal analysis of the whole coarse root systems of four co-occurring species (3D).

\begin{tabular}{|c|c|c|c|c|}
\hline species & id $\left.^{1}\right)$ & $D$ & $D_{x y}$ & $N$ \\
\hline \multirow[t]{5}{*}{ Grewia flava } & 203 & 1.40 & 1.38 & 77452 \\
\hline & 206 & 1.46 & 1.45 & 14616 \\
\hline & 213 & 1.40 & 1.42 & 19712 \\
\hline & 214 & 1.28 & 1.34 & 4080 \\
\hline & 215 & 1.30 & 1.13 & 990 \\
\hline mean & & 1.37 & 1.34 & \\
\hline std & & 0.08 & 0.13 & \\
\hline \multirow[t]{5}{*}{ Strychnos cocculoides } & 405 & 1.50 & 1.35 & 7308 \\
\hline & 409 & 1.17 & 1.09 & 12375 \\
\hline & 412 & 1.26 & 1.28 & 11550 \\
\hline & 425 & 1.37 & 1.32 & 15624 \\
\hline & 426 & 1.22 & 1.22 & 12506 \\
\hline mean & & 1.30 & 1.25 & \\
\hline std & & 0.13 & 0.10 & \\
\hline \multirow[t]{5}{*}{ Strychnos spinosa } & 501 & 1.43 & 1.41 & 31464 \\
\hline & 508 & 1.24 & 1.28 & 30240 \\
\hline & 509 & 1.41 & 1.33 & 1456 \\
\hline & 510 & 1.55 & 1.52 & 6561 \\
\hline & 511 & 1.33 & 1.38 & 8004 \\
\hline mean & & 1.39 & 1.38 & \\
\hline std & & 0.12 & 0.09 & \\
\hline \multirow[t]{5}{*}{ Vangueria infausta } & 706 & 1.60 & 1.56 & 31212 \\
\hline & 708 & 1.33 & 1.43 & 12800 \\
\hline & 711 & 1.34 & 1.45 & 3420 \\
\hline & 712 & 1.62 & 1.39 & 2080 \\
\hline & 713 & 1.66 & 1.50 & 2448 \\
\hline mean & & 1.51 & 1.47 & \\
\hline std & & 0.16 & 0.07 & \\
\hline
\end{tabular}

1) Identifying number of individual.

least-significance-difference test, indicating a difference between these two species at the 5\% level.

However, the different ages of our investigated coarse root systems could also influence $D$. When data from all species were considered in one analysis, the box counting dimension was found to correlate positively with age $\left(R^{2}=0.44\right)$ (figure 7). This age-dependent increase of $D$ seems to be strongly apparent in Grewia flava $\left(R^{2}=0.63\right)$ and Strychnos cocculoides $\left(R^{2}=0.55\right)$ but less pronounced in Vangueria infausta $\left(R^{2}=0.41\right)$ and Strychnos spinosa $\left(R^{2}=0.30\right)$. An analysis of covariance with the species as factor and age as covariable indicated a significant positive influence of age on $D$. The box counting dimensions of Strychnos cocculoides and Vangueria infausta, now at the $1 \%$ level were significantly different.

However, in view of the low number of replicates for the individual species, further investigations will be necessary to fully assess the relationship between age and fractal dimension.
We tried to relate the box counting dimensions of the individual coarse root systems (table II) also to other global parameters characterizing the root systems (cf. table I). The correlation to $D$ was particularly strong in the case of root length density $\delta$ (simply defined as total root length, divided by the volume of the smallest cylinder containing the root system), the coefficient of determination being $R^{2}=0.51$ when all individuals are considered together. Figure 8 shows that this relationship is even closer when only the two Strychnos species are considered separately, and that shape and tightness of the regressions differ considerably between the four species. Root volume density (sum of root segment volume divided by volume of containing cylinder) shows also a clear correlation to $D\left(R^{2}=0.52\right)$ for all 20 individuals taken together (diagram not shown), with similar differences between the species. For other global attributes (total length, maximal radius, maximal depth, collar diameter, mean interbranching distance) the relationships to $D$ are only weak ( $R^{2}$ between 0.01 and 0.20 ).

The box counting dimensions $D$ obtained from full 3$\mathrm{D}$ analysis did not differ by more than 0.23 from the corresponding values $D_{x y}$ (mean: 0.03, std: 0.09) from 2-D analysis of the projections in the $x y$-plane (figure 9 , $\left.R^{2}=0.57\right)$. Statistically, the resulting regression line could not be separated from the angle bisector $D=D_{x y}$ $(p=0.25)$.

\subsubsection{Fine roots}

Table III shows results from the calculation of $D_{x y}$ for the projected fine roots. The used range of grid resolutions was from 0.05 to $3.0 \mathrm{~mm}$. Between the species, no significant differences in the $D_{x y}$ value for the fine roots are apparent.

\section{DISCUSSION}

The analysis suggests that the investigated species, although growing under the same environmental conditions, have different rooting strategies which are expressed in the architectures of the coarse root systems.

Table III. Fractal analysis of fine root samples (2-D).

\begin{tabular}{lccc}
\hline Species & \#samples & $\begin{array}{c}\text { mean } \\
\left(\boldsymbol{D}_{\boldsymbol{x y}}\right)\end{array}$ & $\begin{array}{c}S t d \\
\left(\boldsymbol{D}_{\boldsymbol{x y}}\right)\end{array}$ \\
\hline Grewia flava & 35 & $\mathbf{1 . 4 2}$ & 0.14 \\
Strychnos cocculoides & 28 & $\mathbf{1 . 4 8}$ & 0.12 \\
Strychnos spinosa & 44 & $\mathbf{1 . 4 6}$ & 0.09 \\
Vangueria infausta & 59 & $\mathbf{1 . 4 1}$ & 0.06 \\
\hline
\end{tabular}




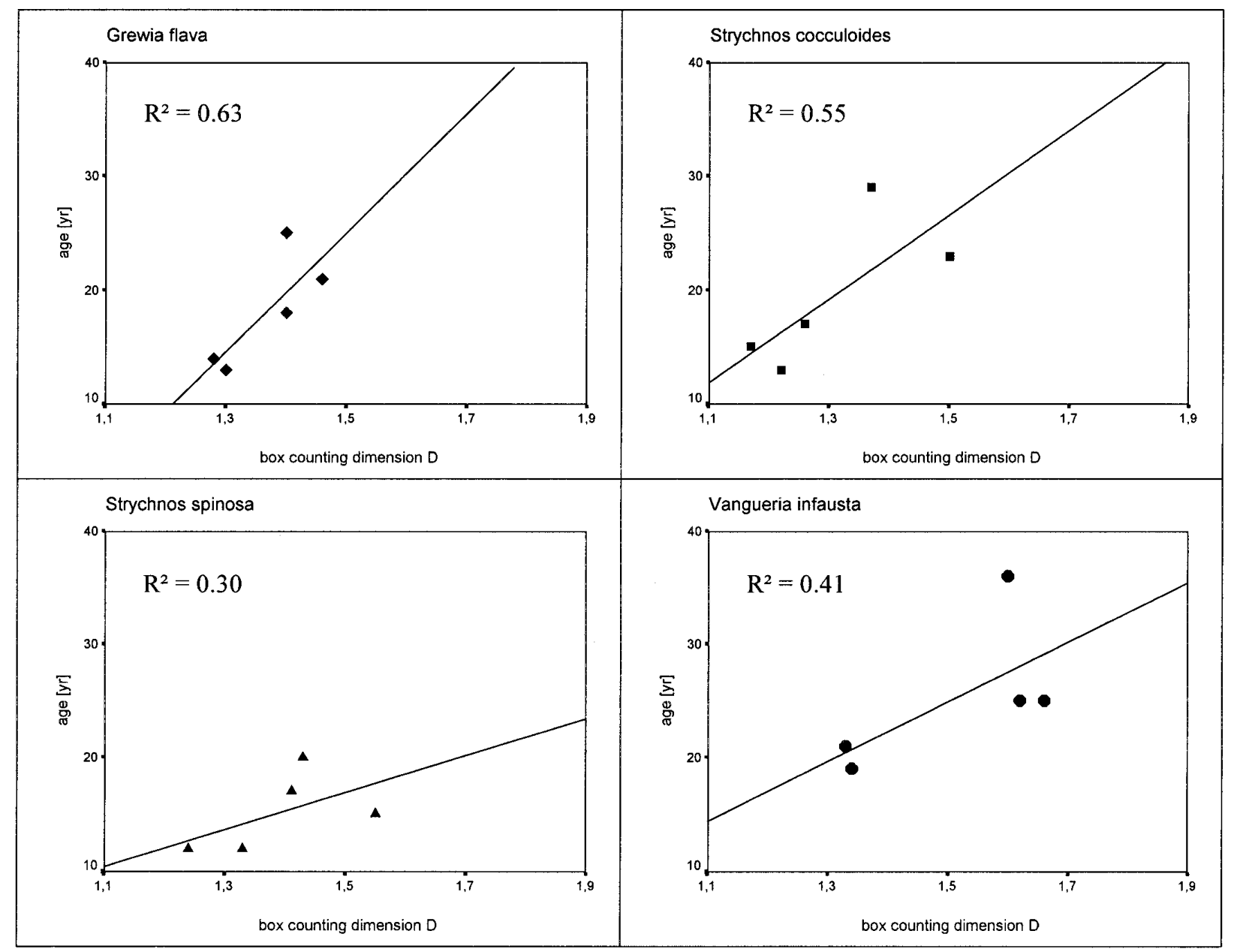

Figure 7. Age vs. box counting dimension D from Grewia flava, Strychnos cocculoides, Strychnos spinosa and Vangueria infausta, with regression line for each species.

Both Strychnos species show a tendency towards deep rooting behaviour. The ecophysiological advantage may be to obtain access to water deep in the soil profile.

The development of coarse root systems in Grewia flava is initially shallow. We suggest that Grewia flava may be able to utilize periodic rain fall, especially low quantities, before the water is evaporating from the soil. Additionally, this feature aids a better nutrition supply from the organic upper horizons. Vangueria infausta shows an intermediate strategy.

On the base of quantitative analysis with GROGRA 3.2 , it was possible to test mathematical models at reconstructed virtual 3-D structures obtained from in situ measurements. Especially the fractal analysis seems to be a useful tool to quantify the exploration of a three dimen- sional space in a given range of scales, although the obtained box-counting dimensions have to be relativized in view of our artificial diameter threshold of $3 \mathrm{~mm}$. In a study of above-ground branching patterns of trees, where all segments down to the smallest diameter were measured (see [29] for details), we applied a fractal analysis with the same set of resolutions on a full system and on a system where all branches weaker than $3 \mathrm{~mm}$ were removed. The resulting dimension was diminished by 0.22 by the removal. We assume that the necessary correction of $D$ will be of the same order of magnitude in the case of our root systems, yielding a "true" $D$ approximately between 1.5 and 1.75 . However, some uncertainty remains as the root branching patterns differ considerably from the above-ground patterns considered in the cited study. 


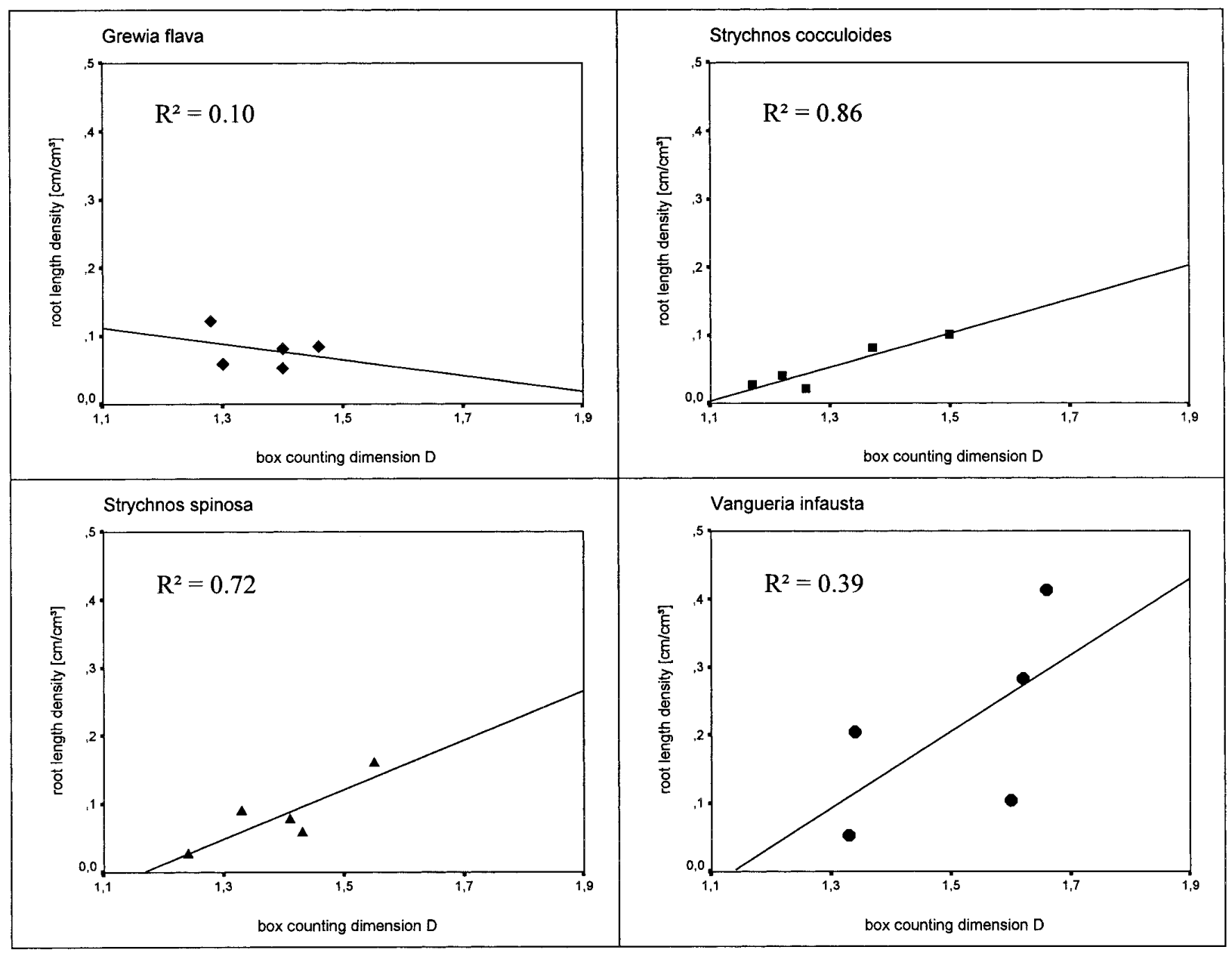

Figure 8. Root length density vs. box counting dimension $D$ from Grewia flava, Strychnos cocculoides, Strychnos spinosa and Vangueria infausta, with regression line for each species.

But, the comparison of different values of $D$ obtained with the same method and under the same restrictions can still indicate different degrees of exploration of the soil, with potential applications on agroforestry systems: The fractal dimension could be one possible indicator for competition between adjacent roots as well as for a more or less strong exploitation of soil resources.

The comparison of the $D$ values with the $D_{x y}$ values obtained from the projections of the root systems into the horizontal plane (figure 9) shows that both dimensions are correlated, and that - over the range of scales consid-

Figure 9. Correlation of box counting dimension $D$ (spatial) $v s$. $D_{\text {yy }}$ (planar projection) from Grewia flava (G.f.), Strychnos cocculoides (S.c.), Strychnos spinosa (S.s.) and Vangueria infausta (V.i.), solid line: linear regression, dotted line: $D=D_{x y}$

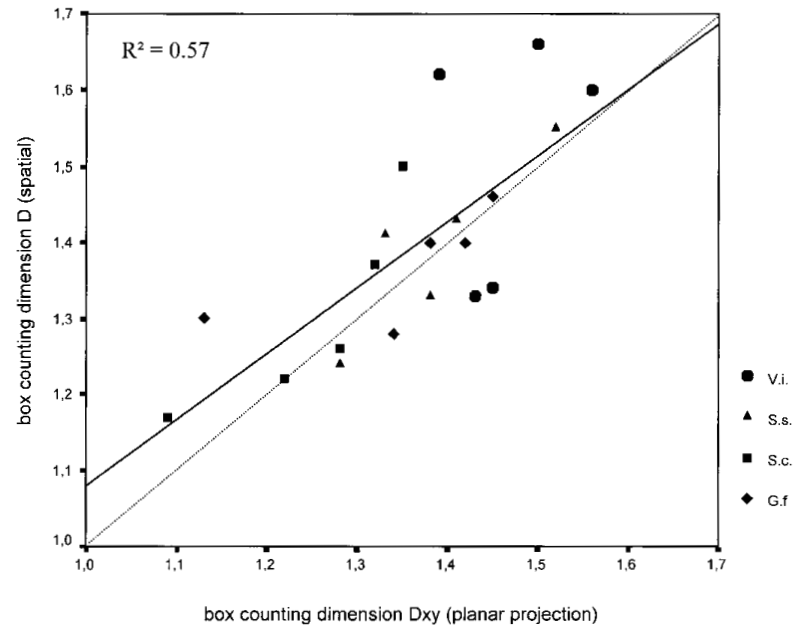


ered, $-D_{x y}$ is not systematically smaller than $D$. However, $43 \%$ of the variation of $D$ cannot be explained by $D_{x y}$. Hence, a considerable loss of information when occurs only the (easier obtainable) dimension of the planar projection is calculated instead of carrying out the full $3-\mathrm{D}$ analysis. However, our findings suggest that the results are not necessarily much worse when an even simpler method of soil exploration assessment is used to replace 3-D fractal analysis, i.e. the determination of overall root length density $\delta$ (cf. figure 8 ). Here, $49 \%$ of the variation of $D$ remain unexplained, which is not much more than in the case when $D_{x y}$ is used to predict $D$. However, the apparent species-dependence of the relationship between $\delta$ and $D$, and the small number of investigated individuals, make a further confirmation of these results desirable.

In the case of our fine root samples, we were restricted to a 2-D analysis method, i.e. we could only determine $D_{x y}$. The fine root samples do not show any significant differences in the box counting dimension between the species, whereas the coarse root systems do. A discrepancy in fractal dimension between coarse and fine root scale seems to occur at least for Grewia flava and Strychnos cocculoides, possibly due to a multifractal behaviour of the root systems, which is not unusual in natural phenomena $[27,34,35]$.

The low variation of the average $D_{x y}$ for fine root samples (1.41-1.48) between the species could be interpreted as an indicator of a species-independent rooting strategy. It seems that fine roots try to reach a certain value under almost similar environmental conditions which may be an optimum value under these growth conditions. Further comparison with similar analyses under different climatological and pedological conditions is needed for an interpretation of this almost constant value for $D_{x y}$.

Results from the analysis of the fractal dimension of the coarse root systems were consistent with the field observations. Strychnos cocculoides with the apparently weakest root system had the lowest box counting dimension $D$. The maximum value of $D$ for Vangueria infausta is in agreement with the branching orders and the branching intensity. These root systems are most intensively exploring the three dimensional space. However, the values of the box counting dimension for Stychnos spinosa and Grewia flava are surprising. From observations in the field it was expected that the latter had the more intensive coarse root system, whereas fractal analysis did not show a significant difference between these species. Surprising is that a higher branching order (maximum for Grewia flava: 3, Strychnos spinosa: 2) seems to be not necessarily a good indicator for the intensity of exploration of the soil.
When these results are considered, one has to keep in mind that the fractal or box counting dimension gives only a very condensed information about the spatial organization of the branching systems in the soil. To gain knowledge about factors influencing the activity of individual root meristems and about the ecophysiological strategies followed by the different species during the complete course of ontogenesis, dynamic studies including the observation of growing roots at different moments in time are probably necessary. We had to restrict ourselves to "static" descriptions. However, static observation also has advantages once the digital reconstruction is performed for a sample of root systems, characteristic features of the branching systems can be quickly detected and precisely quantified.

Acknowledgements: We are grateful to Mmoloki Botite and Golekwang Phiri for excellent assistance in the field, to Stefan Luther for support concerning the software tools, to Martin Worbes for dendrochronological assistance and to Ana M. Tarquis and Amram Eshel for helpful suggestions and literature. Furthermore, we express our thanks to two anonymous referees for their remarks which helped to improve the paper.

\section{REFERENCES}

[1] Barnsley M.F., Fractals Everywhere, Associated Press, Boston, 1988.

[2] Berntson G.M., Fractal geometry, scaling, and the description of plant root architecture, in: Waisel Y., Eshel A., Kafkafi U. (Eds.), Plant Roots: The Hidden Half, Dekker, New York, 2nd ed., 1996, pp. 259-272.

[3] Colin-Belgrand M., Joannes H., Dreyer E., Pagès L., A new data processing system for root growth and ramification analysis: Description of methods, Ann. Sci. For. 46 Suppl. (1989) 305s-309s.

[4] Colin-Belgrand, Pagès L., Dreyer E., Joannes H., Analysis and simulation of the architecture of a growing root system: application to a comparative study of several tree seedlings, Ann. Sci. For. 46 Suppl. (1989) 288-293.

[5] Coutts M.P., Development of the structural root system of Sitka spruce, Forestry 56 (1983) 1-16.

[6] Coutts M.P., Lewis G.J., When is the structural root system determined in Sitka spruce, Plant Soil 71 (1983) 155-160.

[7] De Reffye Ph., Houllier F., Modelling plant growth and architecture: Some recent advances and applications to agronomy and forestry, Current Sci. 73 (1997) 984-992.

[8] De Reffye Ph., Fourcaud Th., Blaise F., Barthélémy D., Houllier, F., A functional model of tree growth and tree architecture, Silva Fenn. 31 (1997) 297-311.

[9] De Reffye Ph., Houllier F., Blaise F., Barthélémy D., Dauzat J., Auclair D., A model simulating above- and belowground tree architecture with agroforestry applications, Agrofor. Syst. 30 (1995) 175-197. 
[10] De Wit P.V., Becker R.P., Explanatory note on the land system map of Botswana. FAO/UNDP/Government of Botswana. Soil Mapping and Advisory Services, Field Doc. 31, 1990.

[11] Deans J.D., Dynamics of coarse root production in a young plantation of Picea sitchensis, Forestry 54 (1981) 139155.

[12] Danjon F., Sinoquet H., Godin C., Colin F., Drexhage M., Characterisation of the structural tree root architecture using digitising and the AMAPmod software, Plant Soil (submitted).

[13] Drexhage M., Gruber F., The architecture of woody root systems of 40-year-old Norway spruce (Picea abies (L.) Karst.): crown-trunk-relations and branching forms, in: Kutschera L. (Ed.), Root Ecology and its Practical Application, Klagenfurt, 1992, pp. 703-706.

[14] Edgar G., Measures, Topology and Fractal Geometry, Springer, New York, 1990.

[15] Eshel A., On the fractal dimension of a root system, Plant, Cell Env. 21 (1998) 247-251.

[16] Falconer K., Fractal Geometry: Mathematical Foundations and Applications, Wiley, New York, 1990.

[17] Fayle D.C.F., Extension and longitudinal growth during the development of Red Pine root systems, Can. J. For. Res. 5 (1975) 109.

[18] Fitter A.H., Stickland T.R., Harvey M.L., Wilson G.W., Architectural analysis of plant root systems. 1 . Architectural correlations of exploitation efficiency, New Phytol. 118 (1991) 375-382.

[19] Godin C., Guédon Y., Costes E., Caraglio Y., Measuring and analysing plants with the AMAPmod software, in: Michalewicz M.T. (Ed.), Advances in Computational Life Sciences, Vol. I: Plants to Ecosystems, CSIRO, Brisbane, 1997, pp. 53-84.

[20] Gruber R., Dynamik und Regeneration der Gehölze, Berichte des Forschungszentrums Waldökosysteme, Ser. A, Vol. 86, Göttingen, 1992.

[21] Hall P., Wood A., On the performance of box-counting estimators of fractal dimension, Biometrika 80 (1993) 246252 .

[22] Hallé F., Oldeman R.A.A., Tomlinson P.B., Tropical Trees and Forests, Springer, Berlin, 1978.

[23] Henderson R., Ford E.D., Rensaw R., Deans, J.D., Morphology of the structural root system of Sitka spruce 1 . Analysis and quantitative description, Forestry 56 (1983) 122135.

[24] Jourdan C., Rey H., Guédon Y., Architectural analysis and modelling of the branching process of the young oil-palm root system, Plant Soil 177 (1995) 63-72.

[25] Jourdan C., Rey H., Modelling and simulation of the architecture and development of the oil-palm (Elaeis guineensis Jacq.) root system I. The model, Plant Soil 190 (1997) 217233.

[26] Jourdan C., Rey H., Architecture and development of the oil-palm (Elaeis guineensis Jacq.) root system, Plant Soil 189 (1997) 33-48.
[27] Kaye B.H., A Random Walk Through Fractal Dimensions, VCH, Weinheim, 1989.

[28] Kurth W., Growth Grammar Interpreter GROGRA 2.4, Berichte des Forschungszentrums Waldökosysteme, Ser. B, Vol. 38, Göttingen, 1994.

[29] Kurth W., Die Simulation der Baumarchitektur mit Wachstumsgrammatiken, Habilitationsschrift, Georg-AugustUniversität Göttingen, 1998.

[30] Kurth W., Anzola Jürgenson G., Triebwachstum und Verzweigung junger Fichten in Abhängigkeit von den beiden Einflußgrößen "Beschattung" und "Wuchsdichte": Datenaufbereitung und -analyse mit GROGRA, in: Pelz D. (Ed.), DVFF Sektion Forstliche Biometrie und Informatik, 10. Tagung Freiburg i. Br. 24.-26. 9. 1997, Biotechn. Fakultät, Ljubljana, 1997, pp. 89-108.

[31] Lungley D.R., The growth of root systems - A numerical computer simulation model, Plant Soil 38 (1973) 145-159.

[32] Lyford W.H., Development of the Root System of Northern Red Oak (Quercus rubra L.), Harvard Forest Paper 21 (1980) 3-30.

[33] Mandelbrot B.B., The Fractal Geometry of Nature, W.H. Freeman, New York, 1982.

[34] Mandelbrot B.B., Multifractal measures, especially for the geophysicist, Pure Appl. Geophys. 131 (1989) 5-42.

[35] Mark D.M., Aronson P.B., Scale-dependent fractal dimensions of topographic surfaces: An empirical investigation, with applications in geomorphology and computer mapping, Math. Geol. 16 (1984) 671-683.

[36] Pagès L., Kervella J., Growth and development of root systems: Geometrical and structural aspects, Acta Biotheor. 38 (1990) 289-302.

[37] Reeve R., A warning about standard errors when estimating the fractal dimension, Comp. Geosci. 18 (1992) 89-91.

[38] Room P.M., Maillette L., Hanan J.S., Module and metamer dynamics and virtual plants, Adv. Ecol. Res. 25 (1994) 105-157.

[39] Sinoquet H., Rivet P., Measurement and visualization of the architecture of an adult tree based on a three-dimensional digitising device, Trees 11 (1997) 265-270.

[40] Stoll P., Modular growth and foraging strategies in rhizome systems of Solidago altissima L. and branches of Pinus sylvestris L., Dissertation, Universität Zürich, Philosophische Fakultät II, 1995.

[41] Strand L., Crown density and fractal dimension, Meddelelser fra Norsk Institutt for Skogforskning 43 (1990) $1-11$.

[42] Tatsumi J., Yamauchi A., Kono Y., Fractal analysis of plant root systems, Ann. Bot. 64 (1989) 499-503.

[43] Theiler J., Statistical precision of dimension estimators, Phys. Rev. A 41 (1990) 3038-3051.

[44] Zeide B., Gresham C.A., Fractal dimensions of tree crowns in three Loblolly pine plantations of coastal South Carolina, Can. J. For. Res. 21 (1991) 1208-1212.

[45] Zeide B., Pfeifer P., A method for estimation of fractal dimension of tree crowns, For. Sci. 37 (1991) 1253-1265. 